Article

\title{
Bio-Inspired Fluorine-Free Self-Cleaning Polymer Coatings
}

\author{
Lionel Wasser ${ }^{1}$, Sara Dalle Vacche ${ }^{1,2} \mathbb{1}$, Feyza Karasu ${ }^{1,+}{ }^{\dagger}$, Luca Müller ${ }^{1}$, Micaela Castellino ${ }^{2,3}$, \\ Alessandra Vitale ${ }^{2} \mathbb{D}$, Roberta Bongiovanni ${ }^{2} \mathbb{D}$ and Yves Leterrier ${ }^{1, * \mathbb{D}}$ \\ 1 Laboratory for Processing of Advanced Composites (LPAC), Ecole Polytechnique Fédérale de \\ Lausanne (EPFL), CH-1015 Lausanne, Switzerland; lionel.wasser@gmail.com (L.W.); \\ sara.dallevacche@polito.it (S.D.V.); feyza.karasukilic@unifr.ch (F.K.); luca.mueller@epfl.ch (L.M.) \\ 2 Department of Applied Science and Technology Politecnico di Torino, Corso Duca degli Abruzzi 24, \\ 10129 Turin, Italy; micaela.castellino@polito.it (M.C.); alessandra.vitale@polito.it (A.V.); \\ roberta.bongiovanni@polito.it (R.B.) \\ 3 Center for Sustainable Future Technologies, CSFT, IIT@Polito, Italian Institute of Technology, \\ Corso Trento 21, 10129 Turin, Italy \\ * Correspondence: yves.leterrier@epfl.ch; Tel.: +41-21-693-4848 \\ $\dagger$ Present address: Adolphe Merkle Institute, University of Fribourg, Chemin des Verdiers 4, \\ 1700 Fribourg, Switzerland.
}

Received: 30 September 2018; Accepted: 26 November 2018; Published: 28 November 2018

\begin{abstract}
Bio-inspired fluorine-free and self-cleaning polymer coatings were developed using a combination of self-assembly and UV-printing processes. Nasturtium and lotus leaves were selected as natural template surfaces. A UV-curable acrylate oligomer and three acrylated siloxane comonomers with different molecular weights were used. The spontaneous migration of the comonomers towards the polymer-air interface was found to be faster for comonomers with higher molecular weight, and enabled to create hydrophobic surfaces with a water contact angle (WCA) of $105^{\circ}$. The replication fidelity was limited for the nasturtium surface, due to a lack of replication of the sub-micron features. It was accurate for the lotus leaf surface whose hierarchical texture, comprising micropapillae and sub-micron crystalloids, was well reproduced in the acrylate/comonomer material. The WCA of synthetic replica of lotus increased from $144^{\circ}$ to $152^{\circ}$ with increasing creep time under pressure to $5 \mathrm{~min}$ prior to polymerization. In spite of a water sliding angle above $10^{\circ}$, the synthetic lotus surface was self-cleaning with water droplets when contaminated with hydrophobic pepper particles, provided that the droplets had some kinetic energy.
\end{abstract}

Keywords: self-cleaning; lotus; nasturtium; siloxane surfactants; acrylates; photopolymerization; UV nanoimprint lithography; PDMS template

\section{Introduction}

Natural superhydrophobic self-cleaning surfaces such as the famous lotus leaf consist of an intrinsic hierarchical structure with epithelial cells of sizes in the micrometer range, and sub-micron, low surface energy epicuticular wax crystals [1,2]. Such structures favor trapping of small air pockets at the interface with water droplets, which considerably reduces the contact area between the droplet and the surface, resulting in the reduction of contact angle hysteresis, tilt angle, and adhesive force. The self-cleaning effect is the removal of dirt particles by the (rain) water, which form droplets that do not 'stick' on the surface and run away with the dirt. The development of bio-inspired synthetic self-cleaning surfaces has stimulated a considerable research effort since more than a decade, leading to remarkable results. However, reported surfaces often rely on environmentally-detrimental 
and cost-intensive approaches. These are primarily based on fluorinated compounds [3] owing to their low surface energy, and to nanoparticles giving rise to nanopatterned structures: some fluorinated compounds-i.e., long chained fluoroalkylic compounds-create concerns for their biopersistency, while nanoparticles are possibly associated with uncontrolled release issues [4]. In addition, many of the demonstrated methods are hardly scalable to cost-effective, large area surfaces $[5,6]$. Efforts to create fluorine-free and scalable self-cleaning surfaces have been initiated in the last few years, including superhydrophobic water-based nanoparticulate dispersions $[7,8]$, sprayed waxes dissolved in supercritical $\mathrm{CO}_{2}$ [9], and various micro/nanotextures impregnated with lubricating liquids $[10,11]$. The present work follows up with the development of low-energy surfaces based on the spontaneous, enthalpy-driven migration of comonomers and resulting segregation at the polymer-air interface [12-16]. It is based on a highly scalable low-pressure, solvent-free, and ambient UV replication process of plant surfaces using a silicone template as demonstrated in a recent work [17]. In this study, one of the main challenges was the reverse migration of the fluorinated surfactant comonomer, from the polymer-air interface back to the bulk, upon contacting the low-surface energy silicone template, and suppression of the superhydrophobic properties. This problem was solved using a flash of UV light to chemically attach the comonomer previously segregated at the polymer surface, prior to UV printing, but this increased the viscosity of the superficial polymer layers, which was detrimental to the low-pressure replication fidelity.

The objective of this work was to produce bio-inspired self-cleaning coatings using siloxane surfactant comonomers as fluorine-free alternatives, and a cost-effective, low-pressure UV printing process. The leaves of two superhydrophobic plants-namely lotus and nasturtium-were selected to create templates. These two plants possess similar epicuticular wax crystals in the form of sub-micron tubules, however they exhibit totally different hierarchical microstructures: the lotus leaf structure is composed of microscale papillae, whereas nasturtium has larger convex epidermal cells $[18,19]$. Attention was also paid to the influence of the molecular weight and concentration of $\mathrm{Si}$ in the surfactant comonomer, and on the reverse migration phenomenon on the superhydrophobic character of synthetic replica of plant surfaces.

\section{Materials and Methods}

\subsection{Materials}

A hyperbranched polyester acrylate oligomer (CN2302, Sartomer, Colombes, France) was selected owing to its low polymerization shrinkage [20], which warrants a very high replication fidelity [21-23]. It has a theoretical functionality of 16 and a real one of 13 , a density of $1.13 \mathrm{~g} \cdot \mathrm{cm}^{-3}$ and a Newtonian viscosity of $0.3 \mathrm{~Pa}$ s at $25^{\circ} \mathrm{C}$. The photo-initiator was diphenyl(2,4,6-trimethylbenzoyl) phosphine oxide (TPO Esacure, Lamberti, Gallarate, Italy). Three different siloxane comonomers were used, namely an acryloxy-terminated polydimethylsiloxane (PDMSat, ABCR GmbH, Karlsruhe, Germany), and two polyether-modified polysiloxane polyurethane acrylates (PESiUA1 and PESiUA2) whose synthesis and structures are described elsewhere [24]. Table 1 provides molecular weight, number of repeating siloxane units, and amount of $\mathrm{Si}$ in the three comonomers.

Table 1. Molecular weight, atomic and mass concentrations of Si for the siloxane comonomers.

\begin{tabular}{cccc}
\hline Siloxane Comonomer & Molecular Weight (g/mol) & Number of $-(\mathbf{S i}-\mathbf{O})-$ Units & Concentration of Si (wt \%) \\
\hline PDMSat & 581 & 3 & 14.5 \\
PESiUA1 & 5600 & 16 & 8.7 \\
PESiUA2 & 10400 & 16 & 4.3 \\
\hline
\end{tabular}

A total of 12 formulations were prepared with the three comonomers, at concentrations equal to $0.5,1,2$, and $5 \mathrm{wt} \%$. For each formulation, the hyperbranched acrylate was first mixed with a concentration of $6 \mathrm{wt} \%$ of $\mathrm{TPO}$ at $75{ }^{\circ} \mathrm{C}$ and stirred for $15 \mathrm{~min}$ using a magnetic stirrer, until the 
mixture was homogenous. The hyperbranched acrylate + TPO was used as the control material and will be referred to as the acrylate in the following. PDMSat formulations were prepared by mixing selected PDMSat amounts with the acrylate at $40{ }^{\circ} \mathrm{C}$ for further $15 \mathrm{~min}$. PESiUA1 and PESiUA2 formulations were more difficult to prepare due to the very high viscosity of these two comonomers, which prevented accurate dosage and homogeneous mixing with the acrylate. To overcome this problem, the comonomers were heated for $10 \mathrm{~min}$ at $50{ }^{\circ} \mathrm{C}$ and selected amounts could be mixed with the acrylate and stirred for at least $12 \mathrm{~h}$ at ambient temperature. All formulations were transparent and stirred again prior to further processing in order to guarantee a good homogeneity.

\subsection{Process Methods}

Flat surfaces were produced in a first step in order to study the migration of siloxane oligomers. $200 \mu \mathrm{m}$ thick coatings were prepared on glass slides using a doctor blade and photopolymerized immediately, or after selected times to allow monomer migration to the free surface exposed to air. Curing was then performed using a $200 \mathrm{~W}$ high-pressure mercury lamp (OmniCure 2000, EXFO, Mississauga, ON, Canada) and a collimator positioned at $12 \mathrm{~cm}$ above the sample during $3 \mathrm{~min}$ under a UV intensity of $75 \mathrm{~mW} \cdot \mathrm{cm}^{-2}$ at the surface of the sample. The light intensity at the surface of the sample was measured between 230 and $410 \mathrm{~nm}$ using a calibrated radiometer (Silver Line, CON-TROL-CURE, Chicago, IL, USA). Notice that for the surfaces photopolymerized under air, the concentration of photoinitiator was high enough to overcome oxygen inhibition, and the cured surfaces were non-sticky and hard. This was further checked by measuring the water contact angle (WCA): Surfaces polymerized under $\mathrm{N}_{2}$ and under air showed the same wettability (see Table 2).

Table 2. WCA and WSA of flat and texturized surfaces, varying air exposure time, creep time, and template materials. ${ }^{1}: 50 \mu \mathrm{L}$ droplets.

\begin{tabular}{|c|c|c|c|c|c|}
\hline Surface & Material & $\begin{array}{l}\text { Air Exposure Prior to } \\
\text { Polymerization (min) }\end{array}$ & Template Material & $\operatorname{WCA}\left({ }^{\circ}\right)$ & WSA $^{1}\left({ }^{\circ}\right)$ \\
\hline \multirow{8}{*}{ Flat } & Acrylate & 0 & Air & $61.0 \pm 1.3$ & - \\
\hline & Acrylate & 0 & $\mathrm{~N}_{2}$ & $61.9 \pm 2.3$ & - \\
\hline & Acrylate & 120 & Air & $71.8 \pm 3.7$ & - \\
\hline & Acrylate +5 wt $\%$ PESiUA2 & 0 & Air & $104.5 \pm 3.6$ & - \\
\hline & Acrylate $+5 \mathrm{wt} \%$ PESiUA2 & 120 & Air & $101.5 \pm 4.0$ & - \\
\hline & PDMS & 0 & Air & $112.7 \pm 4.1$ & - \\
\hline & Acrylate $+5 \mathrm{wt} \%$ PESiUA2 & 0 & PDMS & $91.4 \pm 1.3$ & - \\
\hline & Acrylate +5 wt $\%$ PESiUA2 & 120 & PDMS & $90.7 \pm 1.9$ & - \\
\hline \multirow{4}{*}{ Nasturtium } & Fresh leaf & - & - & $143.9 \pm 1.6$ & - \\
\hline & Acrylate & 0 & PDMS & $100.7 \pm 3.6$ & - \\
\hline & Acrylate +5 wt $\%$ PESiUA2 & 0 & PDMS & $102.0 \pm 2.1$ & - \\
\hline & Acrylate + 5 wt \% PESiUA2 & 120 & PDMS & $103.3 \pm 3.2$ & - \\
\hline \multirow{5}{*}{ Lotus } & Fresh leaf & - & - & $140.2 \pm 0.9$ & - \\
\hline & Acrylate & 0 & PDMS & $139.1 \pm 1.8$ & - \\
\hline & Acrylate $+5 \mathrm{wt} \%$ PESiUA2 & 0 & PDMS & $143.9 \pm 3.1$ & 45 \\
\hline & Acrylate $+5 w t \%$ PESiUA2 & 120 & PDMS & $141.7 \pm 3.3$ & 38 \\
\hline & Acrylate + $5 \mathrm{wt} \%$ PESiUA2 & 0 & PDMS (5 min creep) & $151.6 \pm 1.0$ & 30 \\
\hline
\end{tabular}

Texturized surfaces were produced in a second step. The leaves of two plants were selected, namely lotus (Nelumbo nucifera) and nasturtium (Tropaeolum majus). The WCA of the lotus and nasturtium leaves, reported in Table 2, were found to be approximately $20^{\circ}$ lower than previously reported values of $164^{\circ}$ [25] and $162^{\circ}$ [26], respectively, due to seasonal factors. The surface of the fresh leaves was used as master and was replicated in the formulations using a UV-nanoimprint lithography process (UVNIL) and an intermediate negative polydimethylsiloxane mold (PDMS, SYLGARD ${ }^{\mathrm{TM}}$ 184, Dow, Midland, MI, USA) as detailed in [17]. This soft, vacuum-free and ambient molding technique preserves the delicate biological surfaces from damage and enables to accurately reproduce their nanometer scale features [27,28]. In short, square samples $(2 \mathrm{~cm} \times 2 \mathrm{~cm})$ cut from the leaves were fixed onto Petri dishes. PDMS was mixed with hardener (10:1 ratio). The mixture was homogenized 
manually for 5-10 min and degassed under a reduced pressure of $50.8 \mathrm{kPa}$ for $5 \mathrm{~min}$ and $84.7 \mathrm{kPa}$ for $10 \mathrm{~min}$. It was poured onto the samples and subsequently cured at room temperature for $48 \mathrm{~h}$. A UVNIL tool equipped with independent control of UV exposure and pressure was used to print the composite surface with the PDMS mold. A $200 \mu \mathrm{m}$ thick layer of the liquid formulations was applied on a glass slide using a doctor blade. The PDMS mold was attached to another glass slide and the PDMS surface was put in contact with the liquid formulation under a controlled pressure of 3 bars. Curing was then performed using the same source and same UV dose as for the flat films. The printed surfaces were finally carefully demolded.

\subsection{Characterization Methods}

The water contact angle (WCA) of the polymerized surfaces was measured using a contact angle meter (EasyDrop, Krüss GmbH, Hamburg, Germany) at room temperature, with deionized water and a droplet volume of $10 \mu \mathrm{L}$. Four WCA measurements were made on each sample and the values were averaged. The water sliding angle (WSA) of selected surfaces was measured using a tilting support equipped with a protractor. A droplet of water was placed on the surface of the sample in horizontal position and the support was slowly tilted until the drop started to move. Measurements were made at room temperature using deionized water. The volume of the droplets varied from 10 to $100 \mu \mathrm{L}$.

The kinetics of the photopolymerization process were analyzed in real time during irradiation, by real-time Fourier transform infrared spectroscopy (RT-FTIR, Thermo-Nicolet 5700 spectrometer, Thermo Fisher, Waltham, MA, USA) on $12 \mu \mathrm{m}$ thick coatings. The results are reported in the Supplementary Materials (Figure S1). Three formulations were tested: acrylate control, acrylate with $0.5 \mathrm{wt} \%$ of PESiUA2 and with $5 \mathrm{wt} \%$ of PESiUA2. The coatings were applied on a silicon wafer using a wire-wound Meyer bar; the IR experiments were made immediately or after 120 min exposure to air prior of starting the irradiation. The IR instrument was settled with a resolution of $4 \mathrm{~cm}^{-1}$ and the acquisition rate was $1 \mathrm{~Hz}$. A $200 \mathrm{~W}$ high pressure mercury-xenon lamp (LC8, Hamamatsu, Shizuoka, Japan) was used and the intensity of the UV light was fixed at $66 \mathrm{~mW} \cdot \mathrm{cm}^{-2}$. The conversion was calculated recording the decrease of the area of the absorption band of the $\mathrm{C}=\mathrm{C}$ double bonds with time $t$, using the methacrylate peak at $1636 \mathrm{~cm}^{-1}\left(P_{\mathrm{C}=\mathrm{C}}(t)\right)$ [29]. The peak area of the $\mathrm{C}=\mathrm{O}$ double bond at $1726 \mathrm{~cm}^{-1}\left(P_{\mathrm{C}=\mathrm{O}}\right)$ was chosen as the reference. The degree of conversion $\alpha$ was calculated as

$$
\alpha=1-\frac{P_{\mathrm{C}=\mathrm{C}}(t) / P_{\mathrm{C}=\mathrm{O}}(t)}{P_{\mathrm{C}=\mathrm{C}}(0) / P_{\mathrm{C}=\mathrm{O}}(0)}
$$

The influence of short flashes of UV light on the shear viscosity of selected formulations was determined using oscillatory shear rheometry and a UV-coupling cell (AR2000, TA instruments, New Castle, DE, USA), with a plate-plate geometry of diameter $20 \mathrm{~mm}$ and a gap of $500 \mu \mathrm{m}$. Samples were tested before, and after being illuminated for short periods. A strain amplitude sweep was performed first at $1 \mathrm{~Hz}$ to determine the limit for the linear viscoelastic range. Frequency sweep tests were then performed at a strain amplitude within the linear range, and usually close to $1 \%$. The UV source and light intensity were the same as used for UVNIL experiments $\left(75 \mathrm{~mW} \cdot \mathrm{cm}^{-2}\right)$. The rheology results are reported in the Supplementary Information.

The topography of the polymer surfaces was observed using a scanning electron microscope (SEM, FEI XLF30-FEG, Philips, Amsterdam, The Netherlands). The SEM was operated in high resolution mode using an acceleration voltage of $5 \mathrm{kV}$. The working distance was fixed to $10 \mathrm{~mm}$. The samples were coated with a thin carbon layer of approximately $12 \mathrm{~nm}$ in order to avoid charging effects.

Chemical surface composition was evaluated by means of a PHI 5000 Versa-Probe scanning X-ray photoelectron spectrometer (XPS, PHI Versaprobe 5000, Physical Electronics, Inc., Chanhassen, $\mathrm{MN}$, USA), with a monochromatic Al K $\alpha$ source at $1486.6 \mathrm{eV}$. A spot size of $100 \mu \mathrm{m}$ was used in order to collect the photoelectron signal for both the high resolution (HR) and the survey spectra. The semi-quantitative atomic compositions and deconvolution procedures were obtained using Multipack 9.7 dedicated software. All core level peak energies were referenced to $C 1 s$ peak at 
$284.5 \mathrm{eV}(\mathrm{C}-\mathrm{C})$ and the background contribution has been subtracted by means of a Shirley function. Depth profile has been performed using the $\mathrm{Ar}^{+}$source with a $2 \mathrm{kV}$ ions accelerating voltage, alternate mode with sputter cycle of $30 \mathrm{~s}$ each.

\section{Results and Discussion}

\subsection{Segregation of Siloxane Comonomers towards Polymer-Air Interface}

The influence of the addition of the siloxane comonomers and their concentration on the wettability of the cured polymer surfaces at the air side was investigated by WCA measurements, in view of selecting the comonomer leading to the most hydrophobic surface, and the results are depicted in Figure 1. When photopolymerized onto the glass substrate, the WCA of the pure acrylate was $61^{\circ}$.

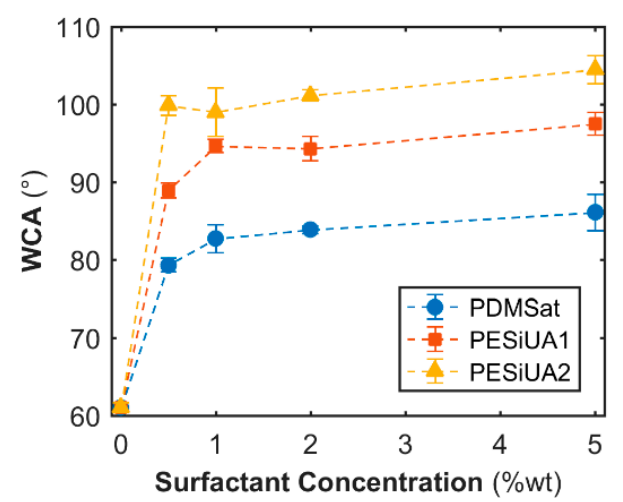

(a)

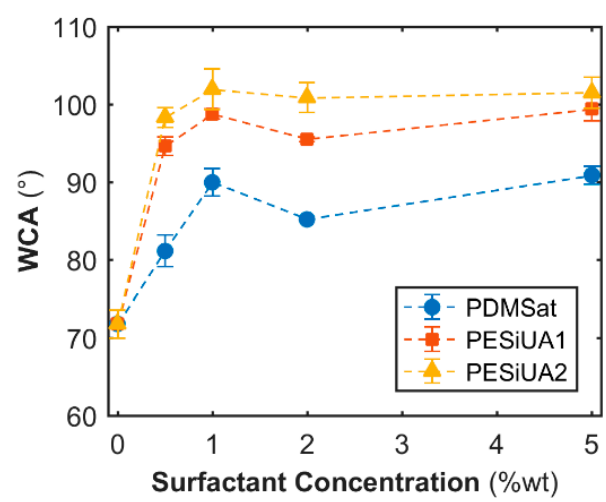

(b)

Figure 1. WCA vs. concentration of siloxane comonomer of flat surfaces polymerized without air exposure (a) and after $120 \mathrm{~min}$ of air exposure (b).

The addition of the three comonomers led to an increase of the WCA up to a saturation level around $1 \mathrm{wt} \%$, beyond which the concentration increase had a marginal influence. Formulations with PESiUAs were beyond the hydrophobic limit independently of the concentration with WCA values comparable to the value for the PESiUAs homopolymers $\left(104^{\circ}\right)$. They were lower than the value of $113^{\circ}$ for the PDMS SYLGARD ${ }^{\mathrm{TM}} 184$ (Table 2), that is close to the maximum WCA of $115.2^{\circ}$ for a flat surface [30]. In contrast PDMSat formulations only reached the hydrophobic limit after an exposure time of $120 \mathrm{~min}$, although the WCA on PDMSat homopolymers were found to be equal to $97^{\circ}$.

Comparing the three siloxane comonomers, it is evident that the parameter influencing the surface activity of the comonomers was the length of the siloxane chain, i.e., the number of siloxane units. PDMSat contains only three units, which were not sufficient to impart a hydrophobic character. The dependence of wettability on the concentration and on the length of the apolar moiety of surface active comonomer has been already reported for fluorinated systems $[17,31,32]$.

As detailed in Supplementary Materials (Figure S2), the delay time between coating application and irradiation processes was effective for the surface modification: comonomers diffused to the polymer-air interface, with a diffusion time depending on the siloxane structure. The higher the molecular weight the faster the diffusion, due to the reduced affinity with the bulk [32]: the PESiUA2 diffusion was immediate after coating, while PESiUA1 and PDMSat required longer times to reach the highest WCA values. In summary, PESiUA2 was the best choice to obtain the highest hydrophobicity of photocured films: it allowed obtaining the highest WCA without a delay time. However, the values were far away from the superhydrophobicity threshold $\left(150^{\circ}\right)$, therefore a change in surface morphology was required besides the modification of the chemical composition of the surface. 


\subsection{Influence of Texturization with PDMS Templates}

The photopolymer showing the highest WCA for flat surfaces (acrylate $+5 \mathrm{wt} \%$ PESiUA2) was used to obtain texturized materials. The acrylate homopolymer was imprinted as reference, and Figure 2 shows the morphology of the synthetic replica of nasturtium and lotus leaves. The nasturtium replica was characterized by entangled island-like epithelial cells with dimensions around $100 \mu \mathrm{m}$ [26]. The lotus replica exhibited a high density of micropapillae of diameter around $10 \mu \mathrm{m}$. A closer look revealed that the sub-micron epicuticular crystal structures were, however, not well replicated, in particular in the case of nasturtium. Such a difference in small-scale structures between the two types of plants was surprising since both natural surfaces are quite similar at this scale, with comparable tubular wax crystal morphologies. A first explanation is related to the possible erosion of the superficial waxes on old leaves [19], which would explain the rather low values of WCA on the nasturtium. In addition, the chemical composition of the lotus and nasturtium waxes differs totally [18], and one additional hypothesis would be that the nasturtium wax tubules partly dissolved in PDMS during the $48 \mathrm{~h}$ curing time [33]. Further work would be needed to clarify the observed differences.
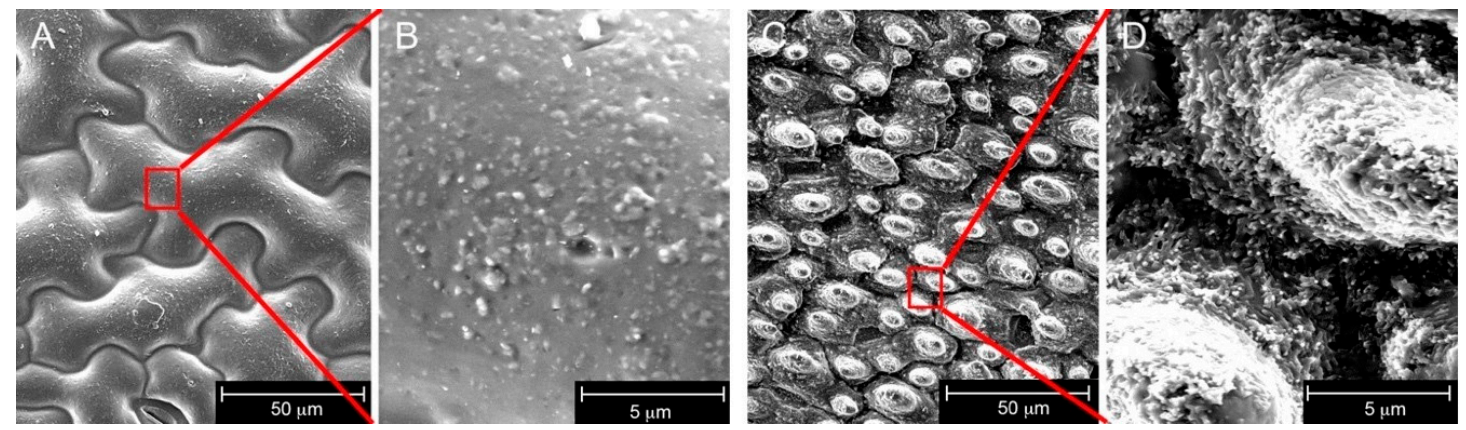

Figure 2. Electron micrographs of the synthetic replica made of photocured acrylate homopolymer: nasturtium (A) and higher magnification inset (B); lotus (C) and higher magnification inset (D).

Table 2 summarizes the WCA data for photopolymers having either flat surfaces or texturized surfaces. The WCA of the synthetic nasturtium surfaces with PESiUA2 comonomer was found to be slightly above $100^{\circ}$, as for the corresponding flat surface, and slightly higher than that of the synthetic nasturtium surface without comonomer. These values were $50^{\circ}$ below the superhydrophobic threshold and some $40^{\circ}$ below the WCA of the fresh nasturtium leaf. This result confirms that the nanosized epicuticular crystal features of the plant, which were not well replicated, are essential to achieve superhydrophobic properties. In contrast, the WCA of the synthetic lotus surfaces with PESiUA2 comonomer was found to be in the range $142^{\circ}-144^{\circ}$, slightly higher than that of the fresh leaf and acrylate lotus surface, and very close to the superhydrophobic limit. In fact, the lotus replica was rather accurate (Figure 2C). This result further indicates the key role of the texture to promote a superhydrophobic state. Nevertheless, the WSA of the synthetic lotus surfaces also reported in Table 2 was rather large and much higher than the WSA of $3^{\circ}$ of the plant, so that these synthetic replicas, although accurate were not superhydrophobic. Additional WSA data are reported in the Supplementary Materials (Table S1).

Surprisingly, the WCA of the flat surfaces with PESiUA2 comonomer polymerized in contact with a flat PDMS mold was $91^{\circ}$, i.e., below the values obtained without using the mold and irrespective of air exposure time prior to curing. This may imply that the contact with the PDMS template during the UV printing process led to a reverse migration of the comonomer as was reported for the case of fluorinated moieties [4]. All these measurements reveal the competing influence of PDMS and presence of siloxane monomer on the surface segregation of the latter.

Figure 3 shows XPS scans of the flat surfaces of acrylate and acrylate with PESiUA2 polymerized with and without $120 \mathrm{~min}$ of exposure to air prior to polymerization, and the lotus texturized surface 
of acrylate with PESiUA2 after 120 min of exposure to air. Apart from carbon and oxygen, present in all the surfaces, Si $2 p$ and N $1 s$ signals were carefully analyzed as fingerprints of the PESiUA2. The relative atomic concentration of these two elements is reported in Table 3. The aim was to first to confirm the migration of the PESiUA2 towards the polymer-air interface, and second to check the presence of this molecule at the surface of the texturized surface. The Si $2 p$ and N $1 s$ signals were indeed absent in the plain acrylate sample. The migration process was confirmed, with an increase of the superficial concentration of these two elements with time prior to polymerization, which is consistent with the increase of WCA with delay time shown in Figure 1. The concentration of Si at the surface of the lotus-texturized sample was found to be higher than that on the flat samples. Possible explanations are the sensitivity of the XPS measurement to surface roughness, and differences in superficial concentration of PESiUA due to different curing kinetics [34], hence different migration processes between the flat and the texturized materials.
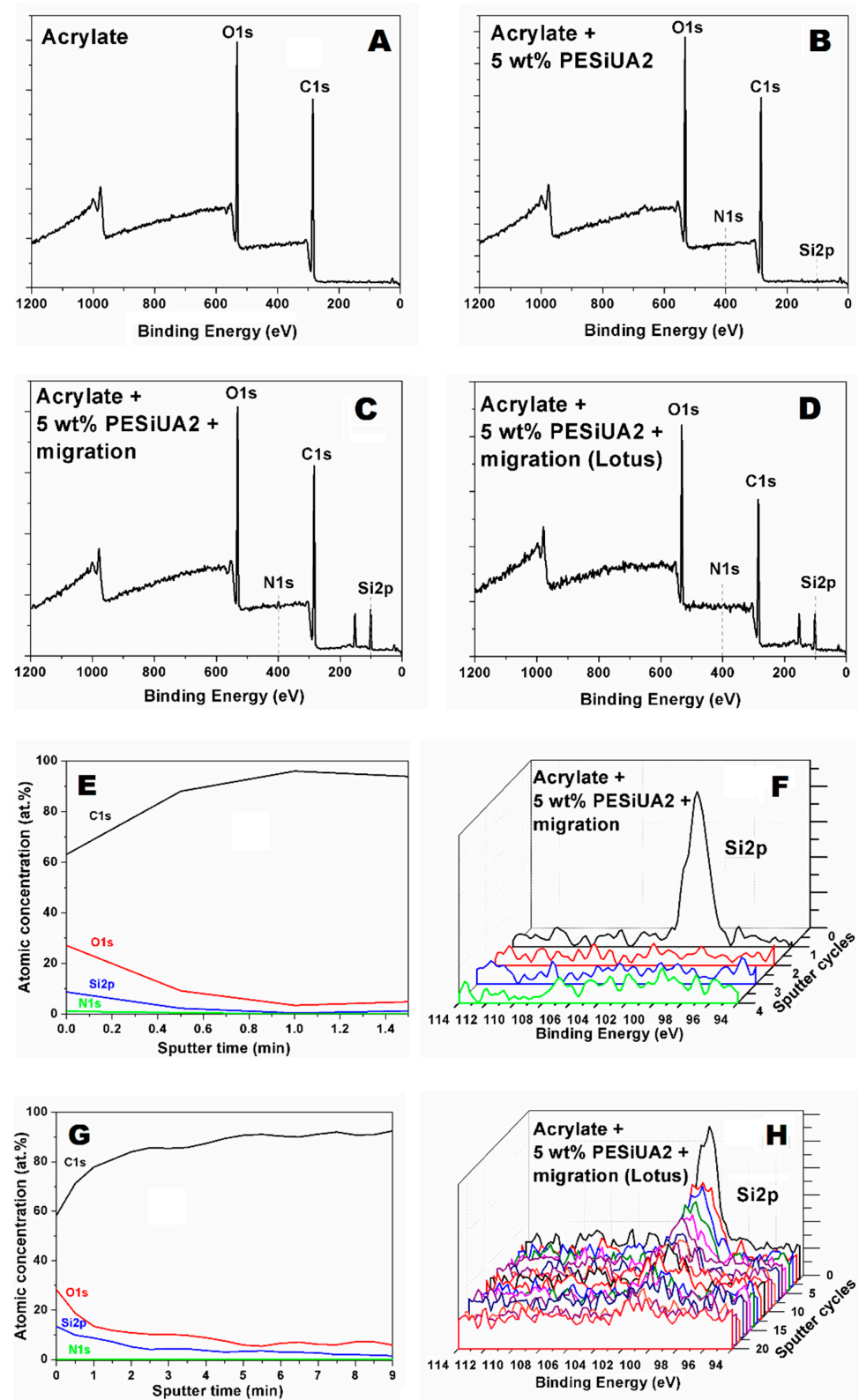

Figure 3. (A-D) XPS Survey scans for the four samples analyzed (see Table 3 for details). C 1s, O 1s, N $1 s$, and Si $2 p$ peaks have been highlighted. Depth profiles of C 1s, O 1s, N 1s, and Si $2 p$ of (E) Sample C and (G) Sample D. Si $2 p$ high resolution curves vs. sputter cycles for (F) Sample C and (H) Sample D. 
Table 3. Relative atomic concentration of $\mathrm{Si}$ and $\mathrm{N}$ at the surface of acrylate with and without PESiUA2, for flat and texturized surfaces.

\begin{tabular}{cccccc}
\hline Sample & Material & $\begin{array}{c}\text { Air Exposure Prior to } \\
\text { Polymerization (min) }\end{array}$ & $\begin{array}{c}\text { Template } \\
\text { Material }\end{array}$ & Si 2p (at.\%) & N 1s (at.\%) \\
\hline A & Acrylate & 0 & air & 0 & 0 \\
B & Acrylate + 5 wt \% PESiUA2 & 0 & air & 1.0 & 2.0 \\
C & Acrylate + 5 wt \% PESiUA2 & 120 & air & 8.5 & 1.3 \\
D & Acrylate + 5 wt \% PESiUA2 & 120 & PDMS (Lotus) & 12.7 & 0.9 \\
\hline
\end{tabular}

The in-depth distribution of $\mathrm{Si}$ in the flat and texturized sample of acrylate with PESiUA2 polymerized after $120 \mathrm{~min}$ of exposure to air was further analyzed by depth-profiling using an $\mathrm{Ar}^{+}$source and is also shown in Figure 3. Assuming an etching rate of $5.5 \mathrm{~nm} / \mathrm{min}$ for acrylate as previously determined for a BEMA-PEGMA siloxane enriched copolymer [35], we can see that there is an exponential decay of the Si $2 p$ signal in the first $5 \mathrm{~nm}$ for the flat sample (Figure 3E), and in the first $10 \mathrm{~nm}$ for the texturized sample, beyond which the signal smoothly decreases till $50 \mathrm{~nm}$ in depth (Figure 3G). In Figure 3F,H, we have reported the Si $2 p$ high resolution curves acquired during depth profiles for the two samples, to better highlight the signal decrease. Again, the differences in depth profiles may result from the sensitivity of the XPS measurement to surface roughness.

The XPS analyses imply that the siloxane comonomers did not fully migrate back into the bulk upon contacting the PDMS surface, in contrast with fluorinated comonomers [4]. To further check this, and totally prevent the trend for reverse migration, flashes of UV light were applied to the free surface of coatings after migration to chemically immobilize the surfactant before UVNIL. Acrylate coatings with $5 \mathrm{wt} \%$ of PESiUA2 exposed to air for $120 \mathrm{~min}$ were flashed for periods of $0.2 \mathrm{~s}$ up to $2 \mathrm{~s}$ before UVNIL with the negative PDMS lotus template. The WCA of the flashed, texturized surfaces turned out to be lower than that of surfaces produced without UV flash. As shown in the Supplementary Materials (Figure S3), this reduction of WCA was due to the large increase of the viscosity of the liquid formulation, by more than four orders of magnitude at low shear rates, and emergence of a yield stress behavior for flashes as short as $0.2 \mathrm{~s}$. This considerable thickening compromised the fidelity of the low-pressure replication process. An alternative strategy was therefore tested, based on viscoelastic creep flow.

\subsection{Influence of Creep}

The low-pressure UVNIL process is fundamentally based on the viscoelastic creep flow of the resin into the sub-micron topography of the PDMS template, so that the replication is pressure and time-dependent. In order to allow the resin to better fill the mold cavities, a pressure of 3 bars was applied to the resin in contact with the PDMS mold for periods up to $10 \mathrm{~min}$ prior to UV curing. Figure 4 shows the influence of creep on the WCA of synthetic lotus surfaces, based on the acrylate with and without $5 \mathrm{wt} \%$ of PESiUA2 (SEM images of these surfaces are shown in Figure S4). In both cases, the WCA increased with creep to a maximum value of $152^{\circ}$ (shown in Figure S5) with PESiUA2 after $5 \mathrm{~min}$ and then decreased. Nevertheless, the WSA reported in Table 2 was found to remain rather high and equal to $30^{\circ}$. 


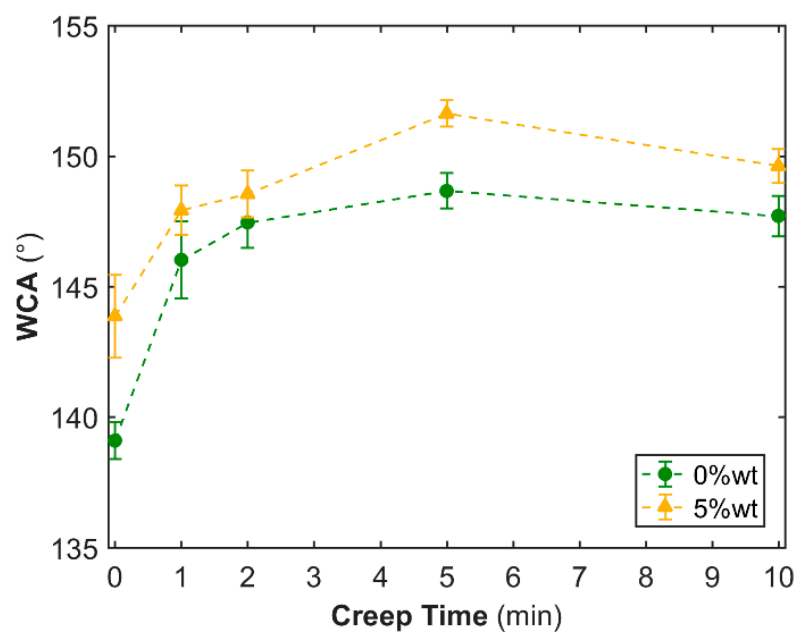

Figure 4. WCA of synthetic lotus surfaces based on acrylate and acrylate $+5 \mathrm{wt} \%$ PESiUA2 vs. creep time under 3 bars prior to UVNIL.

\subsection{Self-Cleaning}

Although the WSA was equal to $30^{\circ}$ the synthetic acrylate + PESiUA2 lotus surface possessed effective self-cleaning properties. This was demonstrated by letting $10 \mu \mathrm{L}$ water droplets fall from a height of $1 \mathrm{~cm}$ on the surface partly covered by ground pepper, on a glass support tilted at a $10^{\circ}$ angle. A sequence of three images taken from a video are shown in Figure 5, where the capture of pepper grains by one bouncing droplet is evident (the video is available in the Supplementary Materials). Notice that, due to its hydrophobicity, ground pepper was reported to be more challenging to remove than other hydrophilic particles such as $\mathrm{MnO}$ and $\mathrm{SiC}$ [8]. The drop velocity upon impact was close to $0.4 \mathrm{~m} / \mathrm{s}$, which was high enough for the drop to bounce on the surface as observed (Figure $5 \mathrm{~b}$ and Video S1 in the Supplementary Materials) [36]. The corresponding kinetic energy of the drop was close to $1 \mu \mathrm{J}$, which again was high enough to overcome the effective interfacial energy $E$ close to $0.07 \mu \mathrm{J}$. The latter was roughly estimated as

$$
E \sim \gamma_{\mathrm{sl}} f \pi R^{2}
$$

where $\gamma_{\mathrm{sl}}$ is the water-polymer interfacial tension, found to be close to $40 \mathrm{~mJ} / \mathrm{m}^{2}$ from the measured WCA data, $f=(\cos \theta+1) /\left(r \cos \theta_{0}+1\right)$ is the wet area fraction calculated and found to be equal to $13 \%$ using the Cassie-Baxter model [37] ( $\theta$ and $\theta_{0}$ represent the WCA of the texturized and flat surfaces, respectively, and $r$ is the roughness factor, equal to 3.2 for lotus), and $R$ is the radius of the droplet at the impact point, evaluated as $2 \mathrm{~mm}$ from the video images. Important to point out is that no such self-cleaning behavior was observed in the case of flat surfaces.

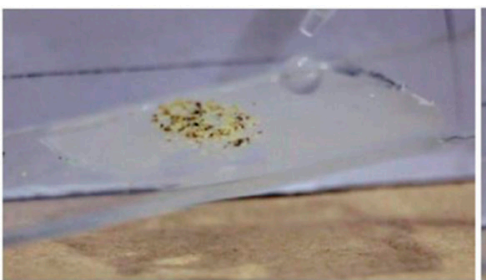

(a)

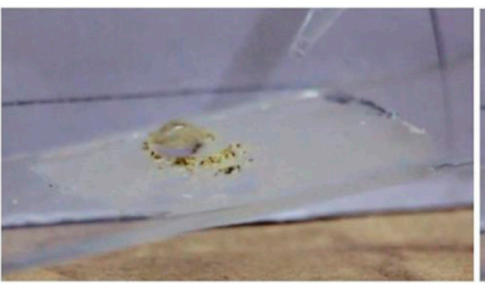

(b)

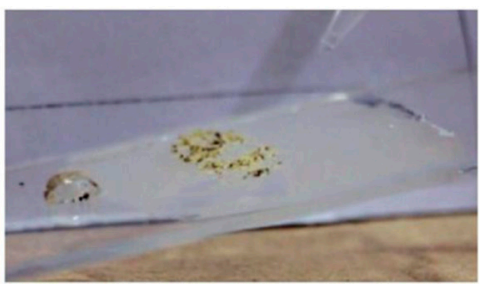

(c)

Figure 5. Sequence of photographs showing the behavior of a water droplet falling (a), bouncing (b), and rolling (c) on a synthetic acrylate lotus surface with $5 \mathrm{wt} \%$ of PESiUA2, printed on a glass support with 1 min of creep under 3 bars. The synthetic lotus surface was contaminated by pepper grains and support was tilted by $10^{\circ}$. Image (b) shows the bouncing droplet with trapped pepper grains, leaving a clean impact trace. Image (c) shows the water drop with trapped pepper grains, sticking on the smooth glass support surface after leaving the printed lotus surface. 
The behavior of the synthetic lotus surface based on the acrylate with $5 \mathrm{wt} \%$ of PESiUA2 to other liquids than water is shown in Figure 6. The difference of contact angle is evident, confirming the hydrophobic character of the surface.

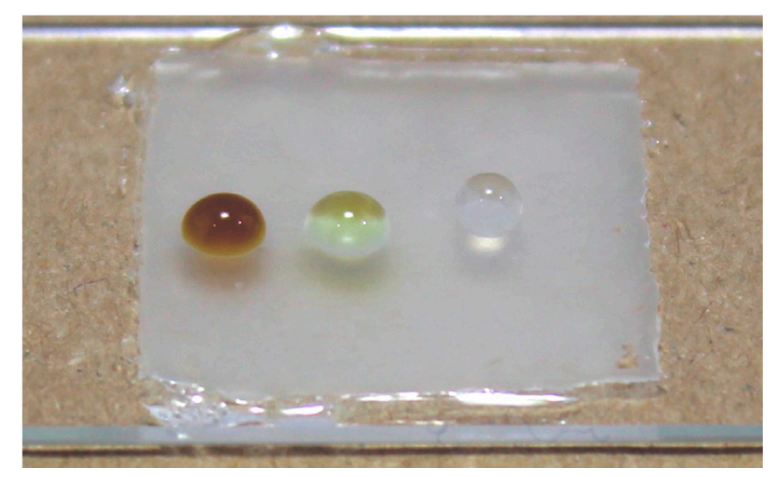

Figure 6. Coffee, olive oil, and water droplets from left to right on a synthetic lotus surface based on acrylate with $5 \mathrm{wt} \%$ PESiUA2 and $120 \mathrm{~min}$ air exposure prior to UVNIL.

\section{Conclusions}

Bio-inspired fluorine free synthetic replica of lotus and nasturtium surfaces were developed in view of obtaining self-cleaning properties, based on an energy efficient UV printing process. A UV-curable acrylate oligomer and three acrylated siloxane comonomers with different molecular weights were used. The process combined the self-assembly of the comonomers at the acrylate/air interface and a UVNIL replication step with a PDMS negative replica of the plant surfaces. The morphology and water contact angle of flat and texturized surfaces were systematically analyzed, leading to the following conclusions.

The migration of the comonomers towards the polymer-air interface led to an increase of the hydrophobicity of the surfaces, from $61^{\circ}$ for the plain acrylate to $105^{\circ}$ for the acrylate with $5 \mathrm{wt} \%$ of PESiUA2 after $30 \mathrm{~min}$ of exposure to air prior to photopolymerization. Comonomers with a higher molecular weight migrated faster.

The replication fidelity was excellent for the lotus leaf surface whose hierarchical texture comprising micropapillae and sub-micron crystalloids was well reproduced in the acrylate/ comonomer material. It was less accurate for the nasturtium surface, with a lack of replication of the sub-micron features. The texturization of the surfaces had a large influence on hydrophobicity. The WCA of synthetic replica of lotus and nasturtium with $5 \mathrm{wt} \%$ of PESiUA2 was equal to $144^{\circ}$ and $102^{\circ}$, respectively. The highest WCA, equal to $152^{\circ}$ was measured on a synthetic lotus surface with $5 \mathrm{wt} \%$ PESiUA2 and 5 min of creep flow under a pressure of 3 bars prior to polymerization. The WSA of this surface was found to be equal to $30^{\circ}$ due to weak adhesion of water. The surface was nevertheless self-cleaning with water droplets when contaminated with hydrophobic pepper particles, provided that the droplets had some kinetic energy.

Supplementary Materials: The following are available online at http://www.mdpi.com/2079-6412/8/12/436/s1, Figure S1: Photoconversion vs. time for HBP and HBP-PESiUA2 (0.5 and 5 wt \%) without and with 120 min of air exposure prior to measurements; Figure S2: WCA vs. air exposure time of flat surfaces of acrylate and acrylate-siloxane formulations: (a) PDMSAT; (b) PESiUA1; and (c) PESiUA2; Figure S3: Viscosity of acrylate (a), acrylate $+0.5 \mathrm{wt} \%$ PESiUA2 (b), acrylate $+5 \mathrm{wt} \%$ PESiUA2 (c) as function of angular frequency, for increasing UV flash duration (0.2-2 s) as indicated; Figure S4: Scanning electron micrographs of the synthetic lotus surfaces, based on the acrylate with $5 \mathrm{wt} \%$ PESiUA2, without (a) and with (b) a creep time of 5 min under a pressure of 3 bars prior to photopolymerization; Figure S5: WCA of $151.9^{\circ}$ measured on a synthetic lotus replica surface with $5 \mathrm{wt} \%$ PESiUA2 and 5 min of creep; Table S1: WSA of synthetic lotus surfaces; Video S1: MVI_8122.mv4.

Author Contributions: Conceptualization, S.D.V. and Y.L.; Data Curation, L.W., L.M., and M.C.; Formal Analysis, L.W., S.D.V., F.K., L.M., M.C., A.V., R.B., and Y.L.; Funding Acquisition, Y.L.; Investigation, L.W., S.D.V., F.K., A.V., R.B., and Y.L.; Methodology, R.B.; Supervision, S.D.V., R.B., and Y.L.; Writing-Original Draft Preparation, L.W. and M.C.; Writing—Review \& Editing, S.D.V., F.K., L.M., A.V., R.B., and Y.L. 
Funding: This research was partly funded by EPFL's Integrated Food and Nutrition Center.

Acknowledgments: The authors acknowledge the Botanical Garden of Lausanne for the supply of fresh plants.

Conflicts of Interest: The authors declare no conflict of interest.

\section{References}

1. Shirtcliffe, N.J.; McHale, G.; Newton, M.I.; Chabrol, G.; Perry, C.C. Dual-scale roughness produces unusually water-repellent surfaces. Adv. Mater. 2004, 16, 1929-1932. [CrossRef]

2. Bhushan, B.; Jung, Y.C. Natural and biomimetic artificial surfaces for superhydrophobicity, self-cleaning, low adhesion, and drag reduction. Prog. Mater. Sci. 2011, 56, 1-108. [CrossRef]

3. Wong, T.-S.; Kang, S.H.; Tang, S.K.Y.; Smythe, E.J.; Hatton, B.D.; Grinthal, A.; Aizenberg, J. Bioinspired self-repairing slippery surfaces with pressure-stable omniphobicity. Nature 2011, 477, 443-447. [CrossRef] [PubMed]

4. Roach, P.; Shirtcliffe, N.J.; Newton, M.I. Progress in superhydrophobic surface development. Soft Matter 2008, 4, 224-240. [CrossRef]

5. Ming, W.; Wu, D.; van Benthem, R.; de With, G. Superhydrophobic films from raspberry-like particles. Nano Lett. 2005, 5, 2298-2301. [CrossRef] [PubMed]

6. Budunoglu, H.; Yildirim, A.; Guler, M.O.; Bayindir, M. Highly transparent, flexible, and thermally stable superhydrophobic ORMOSIL aerogel thin films. ACS Appl. Mater. Interfaces 2011, 3, 539-545. [CrossRef] [PubMed]

7. Mates, J.E.; Ibrahim, R.; Vera, A.; Guggenheim, S.; Qin, J.; Calewarts, D.; Waldroup, D.E.; Megaridis, C.M. Environmentally-safe and transparent superhydrophobic coatings. Green Chem. 2016, 18, 2185-2192. [CrossRef]

8. Schutzius, T.M.; Bayer, I.S.; Qin, J.; Waldroup, D.; Megaridis, C.M. Water-Based, Nonfluorinated dispersions for environmentally benign, large-area, superhydrophobic coatings. ACS Appl. Mater. Interfaces 2013, 5, 13419-13425. [CrossRef] [PubMed]

9. Olin, P.; Hyll, C.; Ovaskainen, L.; Ruda, M.; Schmidt, O.; Turner, C.; Wågberg, L. Development of a semicontinuous spray process for the production of superhydrophobic coatings from supercritical carbon dioxide solutions. Ind. Eng. Chem. Res. 2015, 54, 1059-1067. [CrossRef]

10. Smith, J.D.; Dhiman, R.; Anand, S.; Reza-Garduno, E.; Cohen, R.E.; McKinley, G.H.; Varanasi, K.K. Droplet mobility on lubricant-impregnated surfaces. Soft Matter 2013, 9, 1772-1780. [CrossRef]

11. Schlaich, C.; Yu, L.; Cuellar Camacho, L.; Wei, Q.; Haag, R. Fluorine-free superwetting systems: Construction of environmentally friendly superhydrophilic, superhydrophobic, and slippery surfaces on various substrates. Polym. Chem. 2016, 7, 7446-7454. [CrossRef]

12. Torstensson, M.; Ranby, B.; Hult, A. Monomeric surfactants for surface modification of polymers. Macromolecules 1990, 23, 126-132. [CrossRef]

13. Bongiovanni, R.; Malucelli, G.; Priola, A. Modification of surface properties of UV-cured films in the presence of long chain acrylic monomers. J. Colloid Interface Sci. 1995, 171, 283-287. [CrossRef]

14. Van der Grinten, M.G.D.; Clough, A.S.; Shearmur, T.E.; Bongiovanni, R.; Priola, A. Surface segregation of fluorine-ended monomers. J. Colloid Interface Sci. 1996, 182, 511-515. [CrossRef]

15. Bongiovanni, R.; Sangermano, M.; Medici, A.; Tonelli, C.; Rizza, G. Nanostructured hybrid networks based on highly fluorinated acrylates. J. Sol-Gel Sci. Technol. 2009, 52, 291-298. [CrossRef]

16. Sangermano, M.; Bongiovanni, R.; Longhin, M.; Rizza, G.; Kausch, C.M.; Kim, Y.; Thomas, R.R. Hybrid organic/inorganic UV-cured acrylic films with hydrophobic surface properties. Macromol. Mater. Eng. 2009, 294, 525-531. [CrossRef]

17. González Lazo, A.M.; Katrantzis, I.; Dalle Vacche, S.; Karasu, F.; Leterrier, Y. A Facile in situ and UV printing process for bioinspired self-cleaning surfaces. Materials 2016, 9, 738. [CrossRef] [PubMed]

18. Koch, K.; Dommisse, A.; Barthlott, W. Chemistry and crystal growth of plant wax tubules of lotus (nelumbo nucifera) and nasturtium (tropaeolum majus) leaves on technical substrates. Cryst. Growth Des. 2006, 6, 2571-2578. [CrossRef]

19. Neinhuis, C.; Barthlott, W. Characterization and distribution of water-repellent, self-cleaning plant surfaces. Ann. Bot. 1997, 79, 667-677. [CrossRef] 
20. Schmidt, L.E.; Schmah, D.; Leterrier, Y.; Manson, J.A.E. Time-intensity transformation and internal stress in UV-curable hyperbranched acrylates. Rheol. Acta 2007, 46, 693-701. [CrossRef]

21. Schmidt, L.E.; Yi, S.; Jin, Y.-H.; Leterrier, Y.; Cho, Y.H.; Månson, J.A.E. Acrylated hyperbranched polymer photoresist for ultra-thick and low-stress high aspect ratio micropatterns. J. Micromech. Microeng. 2008, 18, 045022. [CrossRef]

22. Geiser, V.; Jin, Y.H.; Leterrier, Y.; Manson, J.A.E. Nanoimprint lithography with UV-curable hyperbranched polymer nanocomposites. Macromol. Symp. 2010, 296, 144-153. [CrossRef]

23. Geiser, V.; Leterrier, Y.; Månson, J.-A.E. Low-stress hyperbranched polymer/silica nanostructures produced by uv-curing, sol-gel processing and nanoimprint lithography. Macromol. Mater. Eng. 2012, 297, 155-166. [CrossRef]

24. Cheng, J.; Li, M.; Cao, Y.; Gao, Y.; Liu, J.; Sun, F. Synthesis and properties of photopolymerizable bifunctional polyether-modified polysiloxane polyurethane acrylate prepolymer. J. Adhes. Sci. Technol. 2016, 30, 2-12. [CrossRef]

25. Bhushan, B. Biomimetics: Lessons from nature-An overview. Philos. Trans. Royal Soc. A Math. Phys. Eng. Sci. 2009, 367, 1445-1486. [CrossRef] [PubMed]

26. Sharma, C.S.; Abhishek, K.; Katepalli, H.; Sharma, A. Biomimicked superhydrophobic polymeric and carbon surfaces. Ind. Eng. Chem. Res. 2011, 50, 13012-13020. [CrossRef]

27. Sun, M.; Luo, C.; Xu, L.; Ji, H.; Ouyang, Q.; Yu, D.; Chen, Y. Artificial lotus leaf by nanocasting. Langmuir 2005, 21, 8978-8981. [CrossRef] [PubMed]

28. Lee, S.-M.; Kwon, T.H. Effects of intrinsic hydrophobicity on wettability of polymer replicas of a superhydrophobic lotus leaf. J. Micromech. Microeng. 2007, 17, 687. [CrossRef]

29. Vitale, A.; Quaglio, M.; Cocuzza, M.; Pirri, C.F.; Bongiovanni, R. Photopolymerization of a perfluoropolyether oligomer and photolithographic processes for the fabrication of microfluidic devices. Eur. Polym. J. 2012, 48, 1118-1126. [CrossRef]

30. Nakajima, A. Design of hydrophobic surfaces for liquid droplet control. NPG Asia Mater. 2011, 3, 49-56. [CrossRef]

31. Mikhaylova, Y.; Adam, G.; Häussler, L.; Eichhorn, K.-J.; Voit, B. Temperature-dependent FTIR spectroscopic and thermoanalytic studies of hydrogen bonding of hydroxyl (phenolic group) terminated hyperbranched aromatic polyesters. J. Mol. Struct. 2006, 788, 80-88. [CrossRef]

32. Bongiovanni, R.; Di Meo, A.; Pollicino, A.; Priola, A.; Tonelli, C. New perfluoropolyether urethane methacrylates as surface modifiers: Effect of molecular weight and end group structure. React. Funct. Polym. 2008, 68, 189-200. [CrossRef]

33. Lee, J.N.; Park, C.; Whitesides, G.M. Solvent Compatibility of poly(dimethylsiloxane)-based microfluidic devices. Anal. Chem. 2003, 75, 6544-6554. [CrossRef] [PubMed]

34. Vitale, A.; Touzeau, S.; Sun, F.; Bongiovanni, R. Compositional gradients in siloxane copolymers by photocontrolled surface segregation. Macromolecules 2018, 51, 4023-4031. [CrossRef]

35. Sacco, A.; Bella, F.; De La Pierre, S.; Castellino, M.; Bianco, S.; Bongiovanni, R.; Pirri Candido, F. Electrodes/electrolyte interfaces in the presence of a surface-modified photopolymer electrolyte: Application in dye-sensitized solar cells. ChemPhysChem 2015, 16, 960-969. [CrossRef] [PubMed]

36. Richard, D.; Clanet, C.; Quéré, D. Contact time of a bouncing drop. Nature 2002, 417, 811. [CrossRef] [PubMed]

37. Cassie, A.B.D.; Baxter, S. Wettability of porous surfaces. Trans. Faraday Soc. 1944, 40, 546-551. [CrossRef]

(C) 2018 by the authors. Licensee MDPI, Basel, Switzerland. This article is an open access article distributed under the terms and conditions of the Creative Commons Attribution (CC BY) license (http://creativecommons.org/licenses/by/4.0/). 